\title{
Empathy Levels of Dentistry Students in Peru and Argentina
}

\author{
Víctor Patricio Díaz-Narváez1,2*, Fredy Gutierrez-Ventura33, Teresa Varela de Villalba4, \\ Mercedes Salcedo-Rioja ${ }^{5}$, Aracelis Calzadilla-Núñez ${ }^{6}, M^{\prime}$ a Hamdan-Rodríguez ${ }^{7}$, \\ Marcos Cervantes ${ }^{8}$ \\ ${ }^{1}$ Universidad San Sebastián, Santiago, Chile \\ ${ }^{2}$ Universidad Autónoma de Chile, Santiago, Chile \\ ${ }^{3}$ School of Dentistry, Universidad Peruana Cayetano Heredia, Lima, Perú \\ ${ }^{4}$ Universidad Católica de Córdoba, Córdoba, Argentina \\ ${ }^{5}$ School of Dentistry, Universidad Nacional Mayor de San Marcos, Lima, Perú \\ ${ }^{6}$ Hospital Félix Bulnes, Santiago, Chile \\ ${ }^{7}$ School of Nursing, Universidad de Cartagena, Cartagena, Colombia \\ ${ }^{8}$ Faculty of Psychology, Universidad del Norte, Barranquilla, Colombia \\ Email: victor.diaz@uss.cl, fredy.gutierrez@upch.pe, tebeva@hotmail.com, ritasalcedor@hotmail.com, \\ araceliscalza@gmail.com, hamdanm@uninorte.edu.co, marcos.cervantes@gmail.com
}

Received 20 August 2015; accepted 10 October 2015; published 13 October 2015

Copyright (C) 2015 by authors and Scientific Research Publishing Inc.

This work is licensed under the Creative Commons Attribution International License (CC BY).

http://creativecommons.org/licenses/by/4.0/

(c) (i) Open Access

\section{Abstract}

Objectives: To compare the empathy of students in two faculties of Dentistry in Peru and Argentina, three factors were considered: universities, academic year and gender. Material and Methods: Empathy matrices in Dentistry students were measured using the Jefferson Scale of Empathy, culturally validated in Peru and Argentina. Empathy data were compared among and within the faculties tested using a three-factor analysis of variance (model III), a Duncan test, and a discriminant analysis. The level of significance used was less than 0.05 . Results: We found that differences existed between the students tested. The comparison between the levels of empathy in the studied factors and the presence of unexplained variance showed that empathy was able to differentiate populations. Conclusions: The results indicate variability in the empathy values associated with the factors studied. The discriminant test confirms the differences between faculties revealed by the data matrix resulting from the JSE. These differences are possibly due to the effect of educational and social factors.

\section{Keywords}

Empathy, Dentistry Students, Peru, Argentina

\footnotetext{
${ }^{*}$ Corresponding author.
}

How to cite this paper: Díaz-Narváez, V.P., Gutierrez-Ventura, F., de Villalba, T.V., Salcedo-Rioja, M., Calzadilla-Núñez, A., Hamdan-Rodríguez, M. and Cervantes, M. (2015) Empathy Levels of Dentistry Students in Peru and Argentina. Health, 7, 1268-1274. http://dx.doi.org/10.4236/health.2015.710141 


\section{Introduction}

Empathy has been associated with attributes such as prosocial behavior, respect and positive attitudes towards older people, moral reasoning, the absence of bad practices, the ability to gather a patient's medical history and perform a physical examination, achieving patient and doctor satisfaction, attaining a better therapeutic relationship, and obtaining good clinical results [1]-[4]. In addition, Stephenson et al. [5] state that educational and professional organizations have emphasized the need to study empathy and include it in the training of physicians, dentists, and nurses, and in that of all health professionals, as an essential aspect of their professional life. Dentists have a very close to the patient work and empathy is an attribute that improve the patient-dentist relationship.

Empathy is defined upon the basis of three dimensions: 1) adopting a perspective, 2) providing medical care compassionately, and 3) being able to "put oneself in the patient's shoes" [6] [7]. A complex interaction between these dimensions determines the structure of an individual's empathy and his/her empathic response.

The results of the analysis of the data collected in several faculties of dentistry, medicine, nursing, and physiotherapy appear to be contradictory in at least two factors: the academic year the student is in and his/her gender [2]. Very few studies have compared faculties between and within countries. Roh et al. [8] and Kataoka et al. [9] found that empathy levels could vary between countries (Korea and Japan respectively). Variations have also been observed between medical students in a single country and in different countries [4]. These differences have yet to be explained, although it has been hypothesized that they may derive from the diversity of educational cultures, medical practice in itself [4] [6] [7]), the influence of social factors, and other unknown factors [4]. Such differences may open up a "research opportunity concerning the socio-cultural implications that may affect the empathy levels of health professionals in training" [10]. Due to the scarcity of studies comparing empathy levels between universities in a single country and in different countries, and measuring the same factors [4] [8] [9], the present research aims to compare the empathy levels of students attending three dentistry faculties, two in Peru and one in Argentina.

\section{Material and Methods}

This research is exploratory, non-experimental, descriptive, cross-sectional, and ex post facto cause-effect. It was bioethically guided by the Declaration of Helsinki, and received the approval of the Research Ethics Committee of Universidad del Desarrollo and Clínica Alemana, which includes the adoption of informed consent, under signature, as a prerequisite for the implementation of the instrument (approval code CAS-UDD: 2011-64). It studied populations comprising first-to fifth-year students enrolled in the Dentistry or Dentistry programs of the Universidad Peruana Cayetano Heredia (UPCH) [11] ( $\mathrm{n}=258$; 57.3\% of the total students) and the Universidad Nacional Mayor de San Marcos (UNMSM) [12] ( $n=200$; 55\% of the total students) in Peru, and of the Universidad Católica de Córdoba (UCC) [13] ( $\mathrm{n}=189$; 84.8\% of the total students) in Argentina. Data were collected between June and August 2012, almost simultaneously in each of the above faculties. The sample was made up by all the subjects who could be evaluated on the day when the instrument was applied. The scale was applied to all students at the end of the first semester. The participants were tested using the Spanish translation of the Jefferson Scale of Empathy (version S), validated in Mexico and Chile [6] [14], and culturally adapted for Chile [14] [15], Peru, and Argentina by consensus panels [11]-[13]. No exclusion criteria were used, because the objective was to evaluate the relevant variable in the largest number of students possible. Consistent with the above, a neutral individual administered the scale anonymously and confidentially, a single time, in the classrooms of first- to fourth-year students. In the case of fifth-year students, the instrument was applied during a visit to the clinical facilities of each university, following the same criteria mentioned above.

\section{Statistical Analysis}

The sums of the scores of the primary data associated with empathy levels (sum of the observed values of the responses of each of the examined subjects), in the scale mentioned above, were initially evaluated using the Shapiro-Wilk test of normality and Levene's test of homoscedasticity for the three factors studied: University (Faculty), Year, and Gender. The following statistic data were measured: arithmetic mean, standard mean error, and standard deviation in all factors and levels. The comparison of the mean empathy within and between the principal factors and the measurement of the interactions of the principal factors were conducted using a 
three-factor ANOVA (Model III) and a Duncan test (for unbalanced data). Observed power $(1-\beta)$ and effect size $\left(\eta^{2}\right)$ were evaluated. Afterwards, a discriminant analysis was conducted in order to perform the same comparisons mentioned above, but based on the matrices observed in each of the factors studied (answers to each question in the JSE, taken as a whole as independent variables; therefore, each question in the scale was regarded as a "variable" in a matrix of variables and subjects). Wilks' $\lambda$ was used to measure the proportion of the total variance of the discriminant scores not explained by the differences of the factors examined. In order to establish whether the variance and covariance matrices of each Dentistry Faculty come from the same population, Box's M test was used. The centroids of the groups are presented in graphs. Lastly, the percentage of the data correctly classified by university was calculated. The data were processed with SPSS $20.0^{\mathrm{TM}}$. The significance level used was $\alpha \leq 0.05$ and $\beta \leq 0.20$ in all cases.

\section{Results}

Table 1 displays the means, standard mean error, and standard deviation for each of the levels of the factors studied. The application of the three-factor model revealed that the factors "Gender' and 'University" (specifically, a Faculty in a given University), in interaction with the factor Gender, were significant $(p<0.05)$, and that the interaction of the three principal factors (University, Year, and Gender) was highly significant $(p<0.005)$. However, $\eta^{2}$, which indicates the effect size, was small $(0.009,0.012$, and 0.033 respectively). This shows that differences exist, but that they are not great. The observed values of the test's power were $0.675,0.695$, and 0.929 respectively. This shows that only the third value is higher than the minimum acceptable (0.80); in consequence, the risk of committing this Type II error is higher than desirable. Table 2 displays the values of the means of the empathy levels observed and of the Duncan test in each university studied and in the academic years analyzed (without considering the University factor). No significant differences $(p>0.05)$ were observed between the mean empathy levels in the Peruvian universities; however, they differ significantly $(p<0.05)$ from the mean of the Universidad Católica de Córdoba (Argentina). Regarding the academic years examined, three groups can be identified: a first group, formed by the means of the first-, second-, and fourth-year participants, among which no significant differences exist $(p>0.05)$; a second group, which includes the means of the second-, third-, and fourth-year participants, among which no significant differences exist $(p>0.05)$-however, the third year significantly differs $(p<0.05)$ from the first; and lastly, a third group, constituted by fifth-year students only, which significantly differs $(p<0.05)$ from all the other years (Table 2).

The results of the application of the discriminant test based on the matrices of the data observed are shown on Table 3. In all cases, Box's M test was highly significant $(p<0.005)$, which indicates that the covariance matrices compared differ from each other. The model employed yields the highest percentages of correct classification in the comparisons between universities (56.4\%) and between genders in the faculties studied (42.2\%). This indicates that the main variability sources are the University and Gender factors, whereas the percentage of correct classification between academic years drops to $24.7 \%$, despite the statistical significance found. This situation reveals variability between students of different years in the faculties examined, but also indicates that this specific combination between the level of these factors has the lowest variability.

The Wilks' $\lambda$ values observed in the comparison between universities were highly significant $(p<0.0005)$ ( 0.72 and $0.906 ; \chi^{2}=208.41$ and $\chi^{2}=62.427$ respectively in the two cases) when the functions $1-2$ and only 2 are contrasted, which shows that the unexplained variance between the matrices is greater than the explained variance within said matrices. A similar situation was observed when comparing the genders in each university. The Wilks' $\lambda$ values observed were highly significant $(p<0.0005)\left(0.608,0.783\right.$, and $0.871 ; \chi^{2}=314.558 ; \chi^{2}=$ 154.497 , and $\chi^{2}=87.64$ respectively in all cases) when the functions $1-5,2-5$, and $3-5$ are contrasted. This also demonstrates the existence of unexplained variance, and that it is greater than the unexplained variance between the matrices compared. However, when the academic years were compared, also considering the University factor, the Wilks' $\lambda$ values observed were highly significant $(p<0.0005)\left(0.451\right.$ and $0.609 ; \chi^{2}=499.871$ and $\chi^{2}=311.929$ respectively in both cases) when contrasting the discriminant functions $1-14$ and $2-14$. In this case, even though unexplained variance is present, it is smaller than the explained variance, which shows that populations are more homogeneous when the combined factors mentioned above are taken into account.

\section{Discussion}

The objectives of the present study were to describe and compare the empathy level values within and among three 
Table 1. Results of the estimation of empathic orientation means, considering university, year, and gender interaction.

\begin{tabular}{|c|c|c|c|c|c|c|c|}
\hline \multirow{2}{*}{ University } & \multirow{2}{*}{ Year } & \multirow{2}{*}{ Gender } & \multirow{2}{*}{ Mean } & \multirow{2}{*}{$\begin{array}{l}\text { Standard } \\
\text { mean error }\end{array}$} & \multicolumn{2}{|c|}{ Confidence interval: 95\% } & \multirow[b]{2}{*}{ Standard deviation } \\
\hline & & & & & Lower limit & Higher limit & \\
\hline \multirow{10}{*}{$\begin{array}{l}\text { Universidad } \\
\text { Católica de } \\
\text { Córdoba } \\
\text { (UCC) }\end{array}$} & \multirow{2}{*}{ First } & Female & 104.727 & 2.143 & 100.519 & 108.935 & 15.486 \\
\hline & & Male & 92.423 & 2.787 & 86.949 & 97.897 & 15.672 \\
\hline & \multirow{2}{*}{ Second } & Female & 110.261 & 2.964 & 104.440 & 116.081 & 11.250 \\
\hline & & Male & 101.167 & 4.103 & 93.109 & 109.225 & 10.953 \\
\hline & \multirow{2}{*}{ Third } & Female & 110.480 & 2.843 & 104.897 & 116.063 & 13.706 \\
\hline & & Male & 106.000 & 8.206 & 89.884 & 122.116 & 10.817 \\
\hline & \multirow{2}{*}{ Fourth } & Female & 106.200 & 2.595 & 101.104 & 111.296 & 18.925 \\
\hline & & Male & 108.875 & 5.025 & 99.006 & 118.744 & 9.598 \\
\hline & \multirow{2}{*}{ Fifth } & Female & 116.500 & 4.103 & 108.442 & 124.558 & 9.587 \\
\hline & & Male & 102.167 & 5.802 & 90.771 & 113.563 & 19.954 \\
\hline \multirow{10}{*}{$\begin{array}{c}\text { Universidad } \\
\text { Peruana } \\
\text { Cayetano } \\
\text { Heredia } \\
\text { (UPCH) }\end{array}$} & \multirow{2}{*}{ First } & Female & 102.529 & 2.437 & 97.742 & 107.317 & 13.469 \\
\hline & & Male & 113.769 & 3.942 & 106.027 & 121.511 & 9.722 \\
\hline & \multirow{2}{*}{ Second } & Female & 112.133 & 2.119 & 107.972 & 116.295 & 12.396 \\
\hline & & Male & 104.333 & 3.670 & 97.126 & 111.541 & 14.998 \\
\hline & \multirow[b]{2}{*}{ Third } & Female & 111.043 & 2.096 & 106.928 & 115.159 & 14.768 \\
\hline & & Male & 106.800 & 3.178 & 100.558 & 113.042 & 13.664 \\
\hline & \multirow{2}{*}{ Fourth } & Female & 109.081 & 2.337 & 104.492 & 113.670 & 14.068 \\
\hline & & Male & 107.286 & 3.798 & 99.825 & 114.746 & 14.605 \\
\hline & \multirow{2}{*}{ Fifth } & Female & 118.607 & 2.686 & 113.332 & 123.882 & 7.790 \\
\hline & & Male & 101.000 & 5.802 & 89.604 & 112.396 & 10.564 \\
\hline \multirow{10}{*}{$\begin{array}{c}\text { Universidad } \\
\text { Nacional } \\
\text { Mayor de San } \\
\text { Marcos (UNMSM) }\end{array}$} & \multirow{2}{*}{ First } & Female & 96.538 & 2.787 & 91.064 & 102.013 & 10.786 \\
\hline & & Male & 97.538 & 3.942 & 89.796 & 105.280 & 15.009 \\
\hline & \multirow{2}{*}{ Second } & Female & 100.000 & 3.670 & 92.793 & 107.207 & 12.317 \\
\hline & & Male & 99.250 & 4.103 & 91.192 & 107.308 & 16.181 \\
\hline & \multirow{2}{*}{ Third } & Female & 102.778 & 4.738 & 93.473 & 112.082 & 21.347 \\
\hline & & Male & 95.667 & 5.802 & 84.271 & 107.063 & 29.173 \\
\hline & \multirow{2}{*}{ Fourth } & Female & 105.167 & 2.595 & 100.070 & 110.263 & 12.374 \\
\hline & & Male & 120.143 & 3.798 & 112.683 & 127.603 & 16.552 \\
\hline & \multirow{2}{*}{ Fifth } & Female & 97.909 & 3.030 & 91.958 & 103.860 & 16.047 \\
\hline & & Male & 95.000 & 3.101 & 88.909 & 101.091 & 14.873 \\
\hline
\end{tabular}


Table 2. Results of the comparison of the mean empathy between faculties and between the academic years of the dentistry programs studied.

\begin{tabular}{cccc}
\hline Faculty & $\mathrm{n}$ & \multicolumn{2}{c}{ Subset $(\alpha \leq 0.05)$} \\
\hline Universidad Católica de Córdoba (Argentina) & & 105.34 & 2 \\
\hline Universidad Nacional Mayor de San Marcos (Peru) & 189 & 109.19 \\
Universidad Peruana Cayetano Heredia (Peru) & 200 & 109.63 \\
Mean statistical significance within the groups & & 1.00 & 0.744 \\
\hline
\end{tabular}

\begin{tabular}{ccccc}
\hline Academic year & $\mathrm{n}$ & \multicolumn{2}{c}{ Subset $(\alpha \leq 0.05)$} \\
\hline & & 1 & 2 & \\
First & 167 & 105.10 & 107.9 \\
Fourth & 124 & 107.90 & 108.81 \\
Second & 144 & 108.81 & 108.99 & 113.66 \\
Third & 142 & & & 1.00 \\
Fifth & 70 & & 0.574 & \\
\hline
\end{tabular}

Table 3. Results of tests comparing the discriminant array.

\begin{tabular}{cccc} 
Comparisons & F & Box’s M & Significance \\
\hline Among universities & 2.252 & 988.828 & 0.005 \\
Between the genders studied in the faculties & 1.872 & 2166.0 & 0.005 \\
Among the academic years of the faculties studied & 1.60 & 4957.080 & 0.005
\end{tabular}

populations of Dentistry students in two Latin American countries. These results may confirm the existence of variability within and between populations in association with the variable studied. The results obtained suggest the following generalizations: 1 ) there are differences between the Dentistry faculties of the universities examined; 2) females display higher empathy levels than males, with some exceptions; 3) empathy levels tend to increase as students progress in their majors; 4) interactions were observed between the factors studied (year and gender); and 5) the unexplained variance may be the expression of currently unknown factors which influence empathy.

Previous studies conducted in Latin America [2] [10] [15]-[18] and in other continents [19]-[22] only examine this construct in each population in association with the factors mentioned above (year and gender), but do not compare this attribute between student populations. This study shows that the variability of empathy between populations may constitute a trend. In this regard, variability has also been observed in Latin American medical students [4]. Such variability appears to be consistent in empathy level measurements when it is analyzed from a population point of view. This trend is difficult to explain. The interplay between the dimensions of the empathy construct depends on several factors, which can be broadly grouped into biological and social. The latter modulate or interact with anatomo-neuropsychological ones. Therefore, it can be inferred that what the empathy scale really measured is the consequence of a complex process, which is, in addition, ontogenetically constructed [23]-[28] from a subject's young age until his/her maturity. In consequence, the way in which the affective and cognitive components of empathy are integrated with one another should differ between individuals because not all social factors (among others) affect individuals or groups of individuals in the same manner [29]; in addition, because Faculties of Dentistry receive students with varying degrees of empathy, the necessity emerges to take up the task of shaping this attribute in all educational models. Considering that some authors claim that empathy can be learned in higher education (specifically, in the medical sciences [6] [29]-[31]; the 
empathic education of Dentistry students (and of all those whose future professions require empathy), is to some extent in the hands of universities [4].

The results obtained may also be relevant in connection with the possibility of conducting "interventions" in the teaching-learning processes of higher education students, in general, and in those of medical science students, in particular. The variability observed and the inclusion of the factors that account for it may imply that the strategies, methods, and conceptions associated with how empathy can be "taught" in universities depends not only on general, active teaching-learning models, but also on the specific conditions of each student "population". Empathy, as well as its "determinant" or modulating factors, cannot be ignored in the fields of public health and education, because public health or educational policies do not only depend on the resources injected into the system, the structure of the system itself, and the management of its resources, among other aspects: the system is also influenced by how a professional performs in it [1]-[5], specifically in terms of his/her relationship with patients.

\section{Conclusion}

The results of the present study do not demonstrate that the variability found is a rule applicable to all populations. More descriptive information is needed to confirm that this variability constitutes the scientific fact. This study confirms the need to continue researching the following questions: 1) Is variability within and between populations a scientific fact or a mere anomaly? and 2) When there is the variability, which factors are involved in it, and especially, how do they modulate the empathy generation process?

\section{References}

[1] Morales, S. (2012) Estudio del nivel de empatía y motivación de logro de los alumnos de la carrera de odontología de la Universidad de Concepción. Revista de Educación en Ciencias de la Salud, 9, 121-125.

[2] Bilbao, J., Alcócer, A., Salazar, G., et al. (2013) Measurement of Empathetic Orientation in Dentistry Students of Fundación Universitaria San Martín. Puerto Colombia (Atlántico, Colombia). Salud Uninorte (Barranquilla), 29, 3441.

[3] Kane, G.C., Gotto, J.L., Mangione, S., et al. (2007) Jefferson Scale of Patient's Perceptions of Empathy: Preliminary Psychometric Data 2007. Croatian Medical Journal, 48, 81-86.

[4] Díaz-Narváez, V.P., Alonso, L.M., Caro, S.E., et al. (2014) Empathic Orientation among Medical Students from Three Universities in Barranquilla, Colombia and one University in the Dominican Republic. Archivos Argentinos de Pediatría, 112, 41-49.

[5] Stephenson, A., Higgs, R. and Sugarman, J. (2001) Teaching Professional Development in Medical Schools. Lancet, 357, 867-870. http://dx.doi.org/10.1016/S0140-6736(00)04201-X

[6] Alcorta-Garza, A., González-Guerrero, J.F., Tavitas-Herrera, S.E., et al. (2005) Validación de la escala de empatía Médica de Jefferson en estudiantes de medicina mexicanos. Salud Mental, 28, 57-63.

[7] Hojat, M., Mangione, S., Kane, G.C., et al. (2005) Relationship between Scores of the Jefferson Scale of Physician Emphaty (JSPE) and the Interpersonal Reactivity Index (IRI). Medical Teacher, 27, 625-628. http://dx.doi.org/10.1080/01421590500069744

[8] Roh, M., Hahm, B., Lee, D., et al. (2010) Evaluation of Empathy among Korean Medical Students: A Cross-Sectional Study Using the Korean Version of the Jefferson Scale of Physician Empathy. Teaching and Learning in Medicine, 22, 167-171. http://dx.doi.org/10.1080/10401334.2010.488191

[9] Kataoka, H., Koide, N., Ochi, K., et al. (2009) Measurement of Empathy among Japanese Medical Students. Psychometrics and Score Differences by Gender and Level of Medical Education. Academic Medicine, 84, 1192-1197. http://dx.doi.org/10.1097/ACM.0b013e3181b180d4

[10] Silva, M.G., Arboleda, J. and Díaz Narváez, V.P. (2013) Empathic Orientation Dental Students from the Universidad Central del Este. Odontoestomatología, 15, 24-33.

[11] Gutiérrez-Ventura, F., Quezada-Huerta, B., López-Pinedo, M., et al. (2012) Medición del nivel de percepción empática de los estudiantes de la Facultad de Estomatología Roberto Beltrán. Universidad Peruana Cayetano Heredia. Revista Estomatológica Herediana, 22, 91-99.

[12] Salcedo, M.R. and Díaz-Narváez, V.P. Emphaty in Dendal Students of Universidad Nacional Mayor de San Marcos, Peru. Salud Uninorte (Barranquilla), 31, In Press.

[13] Varela, T., Villalba, R.H., Gargantini, P., et al. (2012) Niveles de orientación empática en estudiantes de Odontología 
de la Universidad Católica de Córdoba, Argentina (UCC). Claves de Odontología, 70, 15-22.

[14] Rivera, I., Arratia, R., Zamorano, A., et al. (2011) Measurement of Empathetic Orientation in Dentistry Students. Salud Uninorte (Barranquilla), 27, 63-72.

[15] Rojas-Serey, A.M., Castañeda-Barthelemiez, S. and Parraguez-Infiesta, R.A. (2009) Orientación empática en los estudiantes de dos escuelas de kinesiología de Chile. Educación Médica, 12, 103-109. http://dx.doi.org/10.4321/S1575-18132009000300006

[16] Sánchez, L., Padilla, M., Rivera, I., et al. (2013) Evaluation of Empathetic Orientation in Odontology Students. Educación Médica Superior, 27, 216-225.

[17] Erazo, A.M., Alonso, L.M. and Rivera, I. (2012) Measurement of Empathetic Orientation in Medicine Students of Universidad del Norte. Salud Uninorte (Barranquilla), 28, 354-363.

[18] Howard, M., Navarro, S., Rivera, I., et al. (2013) Measuring the Level of Empathic Orientation in the Student of the Faculty of Dentistry, University of Costa Rica. Odovtos, 15, 21-26.

[19] Chen, D., Lew, R., Hershman, W., et al. (2007) A Cross-Sectional Measurement of Medical Student Empathy. Journal of General Internal Medicine, 22, 1434-1338. http://dx.doi.org/10.1007/s11606-007-0298-X

[20] Nunes, P., Willians, S., Sa, B., et al. (2011) A Study of Empathy Decline in Students from Five Health Disciplines during Their First Year of Training. International Journal of Medical Education, 2, 12-17. http://dx.doi.org/10.5116/ijme.4d47.ddb0

[21] Hojat, M., Vergare, M.J., Maxwell, K., et al. (2009) The Devil Is Third Year: A Longitudinal Study of Erosion of Empathy in Medical School. Academic Medicine, 84, 1182-1191. http://dx.doi.org/10.1097/ACM.0b013e3181b17e55

[22] Beattie, A., Durham, J., Harvey, J., et al. (2012) Does Empathy Change in First-Year Dental Students? European Journal of Dental Education, 16, e111-e116. http://onlinelibrary.wiley.com/doi/10.1111/j.1600-0579.2011.00683.x/full

[23] Garaigordobil, M. and García de Galdeano, P. (2006) Empatía en niños de 10 a 12 años. Psicothema, 18, 180-186.

[24] Rizzolatti, G., Fogassi, L. and Gallese, V. (2006) Mirrors in the Mind. Scientific American, 295, 54-61. http://dx.doi.org/10.1038/scientificamerican1106-54

[25] García-García, E., González, J. and Maestú-Unturbe, F. (2011) Neuronas espejo y teoría de la mente en la explicación de la mente. Ansiedad y Estrés, 17, 265-279.

[26] Arán, V., López, M.B. and Richaud, M.C. (2012) Aproximación Neuropsicológica al Constructo de Empatía: Aspectos Cognitivos y Neuroanatómicos. Cuadernos de Neuropsicología, 6, 63-83.

[27] Shamay-Tsoory, S.G., Aharon, J. and Perry, D. (2009) Two Systems for Empathy: A Double Dissociation between Emotional and Cognitive Empathy in Inferior Frontal Gyrus versus Ventromedial Prefrontal Lesions. Brain, 132, 617 627. http://dx.doi.org/10.1093/brain/awn279

[28] Almonte, C. and Montt, M.A. (2012) Psicopatología infantil y de la adolescencia. 2nd Edition, Mediterráneo, Santiago, 45-58.

[29] Hasan, S., Al-Sharqawi, N., Dashti, F., et al. (2013) Level of Emphathy among Medical Students in Kuwait University, Kuwait. Medical Principles and Practice, 22, 385-338. http://dx.doi.org/10.1159/000348300

[30] Schwartz, B. and Bohay, R. (2012) Can Patients Help Teach Professionalism and Empathy to Dental Students? Adding Patient Videos to a Lecture Course. Journal of Dental Education, 76, 174-184.

[31] Silva, H., Rivera, I., Zamorano, A., et al. (2013) Evaluation of Empathetic Orientation in Dentistry Students of Finis Terrae University in Santiago (Chile). Revista Clinica de Periodoncia, Implantología y Rehabilitación Oral (PIRO), 6, 130-133. 